\title{
Relación de sucesos y literatura de pronósticos: Baltasar Royo y las alteraciones de Aragón en 1588
}

\author{
José antonio Mateos Royo
}

\section{RESUMEN ABSTRACT}

Este artículo analiza una "relación de sucesos" concreta que, precedida de un pronóstico de desgracias y catástrofes, fue escrita por un notario aragonés en el año 1588.

El estudio expone las circunstancias políticas y sociales operantes en Aragón que motivan la redacción de este documento. Revela de igual modo el interés de esta fuente para un mejor conocimiento de la cultura y literatura de la época.
This paper studies a "relación de sucesos", a specific document which is a description of some events. Preceded by a prediction of misfortunes and disasters, this document was written by an Aragonese notary in 1588. The research shows the social and political circumstances taking place in Aragon that motivated its redaction. This article also reveals the interest of this primary source for a better understanding of the culture and literature during this period.

Sin duda alguna, el año de 1588 se había mostrado en Aragón pródigo en exceso en convulsiones de variada índole. De hecho, su extraordinaria acumulación en un plazo breve de tiempo había provocado en la conciencia de las gentes la sensación de vivir un momento de fuertes alteraciones del orden establecido. Esta misma percepción indujo a Baltasar Royo, notario residente en Zaragoza con fuertes vínculos con el Bajo Aragón, a redactar una sucinta relación en prosa de los principales sucesos acaecidos en el reino durante ese año. Ya sea por propio convencimiento o como mera licencia literaria, el autor relacionó los hechos narrados en su 
relato con un supuesto antiguo pronóstico que, escrito en versos latinos, auspiciaba para el mundo grandes transtornos en la fecha citada. El presente estudio intenta situar dicho escrito en su contexto histórico y literario con objeto de determinar sus causas, sus características y su papel en la narrativa de la época.

\section{EL CONTEXTO HISTÓRICO: ARAGÓN A FINES DEL SIGLO XVI}

En fuerte contraste con la palpable expansión existente en diversas esferas - demográfica y económica, artística y cultural-, el Aragón del Quinientos se manifiesta a todas luces como un territorio convulso ${ }^{1}$. Alteraciones sociales de diverso signo pautan toda la centuria para recrudecerse en sus décadas finales. Contiendas entre concejos, de especial intensidad en el primer tercio del siglo XVI, luchas de bandos locales o enfrentamientos entre casas nobiliarias recorren la geografía aragonesa. Largos conflictos antiseñoriales surgen en el señorío de Ariza, la baronía de Monclús y el condado de Ribagorza. El bandolerismo se adueña de buena parte del Norte y Este de Aragón durante la segunda mitad del siglo. Montañeses procedentes del valle de Tena y Jaca unidos a cuadrillas de bandidos devastan en 1588 las poblaciones moriscas de Codo y Pina. Rumores relativos a alzamientos de los nuevos convertidos aragoneses y valencianos, apoyados por turcos, piratas berberiscos o franceses, despiertan recelo y temor entre los cristianos viejos en las décadas finales del Quinientos.

Junto a estas alteraciones sociales, una larga serie de conflictos políticos estallarán a lo largo del siglo entre rey y reino. En el proceso de creación del incipiente Estado moderno, este enfrentamiento se sustancia en los intentos de la monarquía por dotarse de mayores y mejores instrumentos de control frente a las instituciones públicas del reino y su normativa foral. Entre las principales causas de tensiones se cuentan la actuación del Santo Oficio en territorio aragonés, la designación real de personas no regnícolas para altos cargos eclesiásticos y políticos -incluido el de virrey - en el reino, la defensa por Zaragoza del privilegio de los Veinte por encima de los fueros, las intromisiones de la monarquía en materia judicial y sus reformas del régimen foral particular existente en las Comunidades de aldeas de Teruel y Albarracín. Estos y otros enfrentamientos motivaron la paulatina división de muchos aragoneses en

1 Colas, G. y SALAS, J.A., Aragón en el siglo xvI: alteraciones sociales y conflictos politicos. Zaragoza. Universidad, 1982. 
los denominados bandos fuerista y realista. El conocido caso de Antonio Pérez desata en 1591 el conflicto definitivo entre rey y reino con la victoria final de la monarquía, sustanciada en las reformas del sistema foral aragonés aprobadas por las Cortes celebradas en Tarazona en 1592.

Dentro de este contexto histórico, el relato redactado por Baltasar Royo se ciñe en el tiempo de forma estricta al año 1588. Los hechos narrados, con la excepción del episodio de la Armada Invencible, se circunscriben en el espacio al reino aragonés. Las miras locales del autor resultan aún más evidentes en el interés dedicado en su escrito al Bajo Aragón. Así, los acontecimientos que tienen lugar en la denominada Tierra Baja - como las dos noticias sobre supuestos alzamientos moriscos- son tratados con un mayor detenimiento, pese a sus menores repercusiones efectivas. Acaecidos en su mayoría en comarcas próximas, los sucesos restantes no sólo son relatados con una mayor brevedad, sino retomados por el autor para explicar la reacción suscitada en el Bajo Aragón ante su conocimiento. Un buen ejemplo de esta perspectiva localista es la enumeración de los cargos militares designados en marzo de 1588 por parte de las Bailias en la Tierra Baja, ${ }^{2}$ o los síndicos nombrados en agosto para tratar en Zaragoza el proyecto de unión y desafuero general de todos los Concejos aragoneses para luchar contra el bandidaje.

La selección realizada por Baltasar Royo de los mayores males padecidos por el Aragón de la época, basada en los sucesos de 1588, resulta muy ilustrativa. El deterioro de la convivencia entre cristianos nuevos y viejos, el bandolerismo y los alzamientos antiseñoriales, ejemplificados en el largo conflicto del condado de Ribagorza, se constituirían en las principales amenazas para el sosiego del reino. Las convulsiones sociales, en suma, preocupan al autor en mucho mayor grado que los conflictos políticos entre la monarquía y las instituciones del reino. Ninguna mención se hace así al pleito del virrey extranjero ${ }^{3}$, iniciado a fines de 1587 al reclamar Felipe II ante la corte del Justicia de Aragón su derecho de nombrar a extranjeros para el cargo, acción que desata en los años siguientes la aparición de gran número de pasquines políticos contrarios al monarca. Los problemas de orden público primarían de este modo en el ánimo del escritor sobre la causa fuerista.

\footnotetext{
2 El texto se refiere con esta expresión a las Bailias de Cantavieja, Castellote y Aliaga, circunscripciones administrativas que agrupaban los dominios de la Orden de San Juan de Jerusalén sitos en el Bajo Aragón.

3 Colas, G. y Salas, J.A., Aragón en el siglo xvi..., op. cit., pp. 624-631.
} 
Desde su propia perspectiva, la narración de Baltasar Royo confirma diversas características de las tensiones sociales citadas. En primer lugar, el alto grado de conflictividad padecido por la sociedad aragonesa a fines del siglo xvI. En segundo término, los serios problemas experimentados por los poderes públicos para poner coto a violencias y desórdenes en el reino. Por último, la frecuente confluencia de enfrentamientos de diverso signo, con las consiguientes mayores dificultades para las autoridades públicas a la hora de intentar ponerles término.

Esta interacción de unos conflictos con otros se ejemplifica a la perfección en la evolución del bandolerismo ${ }^{4}$. Este se conforma en Aragón como fenómeno social a nivel de reino en la década de los cuarenta y registra manifestaciones de especial dureza en los períodos 1561-72 y 1578-88. Alcanza en la segunda mitad de siglo todos los registros posibles de violencia desde los saqueos de municipios al asesinato a sueldo. La gran frecuencia de asaltos en caminos amenaza la fluidez de las principales rutas comerciales del reino con Cataluña y Francia. Esta expansión del bandolerismo lo vincula a los otros conflictos sociales tratados por Baltasar Royo. Como excusa para el saqueo, cuadrillas de bandidos se unen a los pastores montañeses en sus ataques a las poblaciones moriscas de Codo y Pina. En busca de protección y salario, muchos bandoleros se ponen al servicio de vasallos y señores en las luchas de Ribagorza, como ya había sucedido en los conflictos de Monclús y Ariza o en el pleito sobre la baronía de Ayerbe. Las tensiones entre fueristas y realistas permiten la contratación de bandoleros por unos y otros, como se evidencia en las alteraciones de Teruel.

La relación de Baltasar Royo destila de forma perceptible un sentimiento de impotencia ante la ineficacia de los poderes públicos en la

4 Colas, G. y Salas, J.A., Aragón en el siglo xvi... op. cit., pp. 153-276 y «Delincuencia y represión en el reino de Aragón», Estudios, (1979), pp. 151-165. El bandolerismo alcanza cotas alarmantes en numerosas zonas del área mediterránea bajo el control del Imperio hispánico durante los siglos xVI y xvii. Cataluña, por ejemplo, cuenta con numerosos estudios sobre el tema. Véase REgLA, J., Bandolers, pirates i hugonots. Barcelona, Biblioteca Selecta, 1969 y El bandolerisme català al temps del Barroc. Barcelona, Editora 62, 1966; LLADONOSA, J., El bandolerisme a la Catalunya occidental (1473-1616). Barcelona, Rafael Dalmau, 1972; SALES, N., Senyors bandolers, miquelets $i$ botiflers. Estudis d' historia de Catalunya (segles XVI al xvili). Barcelona, Empuries, 1984 y lBARS, T., "La delincuencia de la Lérida del siglo xVI1" en Primer Congrés d'Historia Moderna de Catalunya, Barcelona, Universitai de Barcelona, 1984, vol. I, pp. 457-462. Para Valencia, véase GARciA, S., Bandolerismo, piratería y control de moriscos en Valencia durante el reinado de Felipe 1I. Valencia, Universidad, 1977 y CASEY, J., "Bandos y bandolerismo en la Valencia Moderna", ell Homenatge al Dr. Sebastián Garcia Martinez. Valencia, Universidad, 1988, vol. I, pp. 407421. Sobre Mallorca, SerRA, J., Els bandolers à Mallorca. Mallorca, El Tall, 1997. Para el caso de Nápoles, VILLARI, R. La revuelta antiespañola de Nápoles. Los origenes (1585-1647). Madrid, Alianza, 1979, pp. 74-99. 
contención de toda esta violencia ${ }^{5}$. Así se refleja en la descripción del fracaso de la importante expedición organizada por el Justicia de Aragón, Juan de Lanuza el Viejo, en el verano de 1588 contra los bandoleros. Los particularismos locales y las distintas situaciones legales y jurisdicciones existentes en el reino dificultaban la eficiente persecución de los delincuentes por parte de las autoridades. Esta sensación de inseguridad se veía agravada por la presencia de bandoleros catalanes, franceses y -en menor medida - valencianos en Aragón, sobre todo en la Ribagorza y en los Monegros. La cercanía de Francia y Cataluña permitía a los bandidos activos en estos territorios evadir la Justicia aragonesa al cruzar la frontera y actuaban así con casi completa impunidad.

El pasaje dedicado en el relato a la supuesta conspiración morisca en el Bajo Aragón resulta de igual modo significativo ${ }^{6}$. En las décadas finales del siglo XVI menudeaban los rumores sobre un alzamiento de los moriscos aragoneses y valencianos, apoyados por tropas francesas, piratas berberiscos o el poderoso Imperio otomano ${ }^{7}$. Los temores despertados en Aragón ya en 1558 tras extenderse la noticia de la toma de Ciudadela, en Menorca, y de un supuesto inminente ataque a Barcelona por parte de una flota turca aumentarán en 1569 ante la sublevación de los moriscos granadinos. Si un edicto de desarme de los cristianos nuevos aragoneses dictado por la Inquisición en 1559 fue anulado por la presión de los nobles aragoneses, esta medida fue finalmente aprobada por el rey Felipe II y llevada a efecto en 1575 y 1593.

En este contexto político, la desconfianza por parte de la monarquía, las autoridades públicas aragonesas y el Santo Oficio sobre la minoría morisca se extremaba en el Bajo Aragón, dada su proximidad al reino de Valencia.

5 Colas, G. y SALAS, J.A.,Aragón en el siglo xvI..., op. cit., pp. 276-411. La expedición realizada en 1588 por el Justicia de Aragón es descrita en las pp. 397-401.

6 El grado de integración de los moriscos en la sociedad aragonesa ha suscitado controversias. Los últimos estudios más renovadores, realizados por Gregorio Colás, intentan superar las lecturas derivadas de las opiniones de las autoridades de la época, en especial la monarquía y la Inquisición. La evidente complejidad de las relaciones entre ambas Comunidades evidencia la necesidad de mayores estudios locales. Véase COLAS, G., "Los moriscos aragoneses y su expulsión" en Destierros aragoneses. Zaragoza, IFC, 1988, vol. I, pp. 189-215; "Cristianos y moriscos en Aragón: una nueva lectura de sus relaciones y comportamientos en el marco de la sociedad rural", Mélanges de la Casa de Velázquez, XXIX-2, (1993), pp. 153-169 y "Los moriscos aragoneses. Una definición más allá de la religión y la politica", Sharq al-Andalus, 12, (1995), pp. 147-161.

7 Regla, J., Estudios sobre los moriscos. Barcelona, Ariel, 1974, pp.70-78 y CARRASCO, M.S., El problema morisco en Aragón a comienzos del reinado de Felipe II. Valencia, Artes Gráficas Soler, 1969. Diversas noticias sobre estas pretendidas conspiraciones moriscas en Aragón entre 1569 y 1583 se hallan en SANCHEZ, P., Organización y jurisdicción inquisitorial: el tribunal de Zaragoza, 1568-1646. Barcelona, Universidad Autónoma, 1989, tesis doctoral inédita. 
Los rumores sobre conspiraciones en la zona, frecuentes a partir de 1569, alcanzan su apogeo en 1577 y 1588. Sin embargo, estas alarmas cesaban siempre con la detención de los principales implicados. El morisco Enrique Compañero ${ }^{8}$, vecino de Zaragoza, es quemado así durante un auto de fe celebrado en la capital del reino en 1581. Había sido acusado ante el Santo Oficio de haber aceptado restaurar el reino moro de Zaragoza - como sucede con el caudillo Germán del relato, asume el título de rey- tras la victoria de un complot planeado por el morisco valenciano Jaime Izquierdo en connivencia con agentes turcos. En este clima de recelo, la convivencia entre ambas Comunidades se resiente de forma palpable en todo el reino y alcanza en determinadas ocasiones cotas preocupantes.

La villa de Calanda, dominio de la Orden de Calatrava y núcleo de la supuesta conspiración urdida en 1588 en la Tierra Baja, resulta un ejemplo extremo de estas tensiones ${ }^{9}$. Vasallos de señorío, al igual que la mayoría de los moriscos del reino ${ }^{10}$, los cristianos nuevos debían pagar en Calanda rentas más onerosas que en los restantes poblaciones del Bajo Aragón vasallas de la Orden -Alcañiz, Belmonte, Castelserás, La Mata, Molinos- habitadas por cristianos viejos. Como en el resto del territorio aragonés ${ }^{11}$, el Santo Oficio se aplica con dureza creciente en la segunda mitad del siglo XVI sobre su mayoritaria población morisca. Todo acto cultural propio de los cristianos nuevos era visto por la Iglesia como un obstáculo para su adoctrinamiento en la religión católica, según demuestra esta prohibición de efectuar representaciones teatrales dispuesta en enero de 1593 tras una visita pastoral:

8 El complot protagonizado por Enrique Compañero y Jaime Izquierdo, en CARRASCO, M.S., El problema morisco... op. cit., p. 40. Natural de Huesca, la familia Compañero se había afincado a fines del siglo xvı en Zaragoza y Calanda. Varios de sus miembros serán procesados durante la década de los ochenta por el Santo Oficio, acusados de participar en estas supuestas sublevaciones, amén de practicar la fe musulmana. Véase CONTE, A., "La Inquisición y los moriscos de la ciudad de Huesca" en Homenaje a Don Antonio Durán Gudiol. Huesca, Instituto de Estudios Altoaragoneses, 1995, pp. 213-227, en especial, pp.219-226. La presencia de una rama de esta familia en Calanda pudo incluso incentivar la creencia por las autoridades aragonesas de que en esta villa se fraguaba la sublevación de 1588.

9 Sánchez, P. y Serrano, E., "Moriscos, Inquisición y conflictividad antiseñorial: Calanda, 1569-1610", en Destierros aragoneses. Zaragoza, IFC, 1988, vol. I, pp. 53-364. Este trabajo confirma en la página 357 los rumores existentes en el Bajo Aragón sobre un alzamiento morisco en 1577. Véase asimismo Carrasco, M.S., El problema morisco..., op. cit., pp. 15, 31-32.

10 Sobre el tema, Colas, G., "El régimen señorial en Aragón”, Jerónimo Zurita, 58, (1988), pp. 9-29 y Serrano, E., "Los señoríos aragoneses de la Orden de Calatrava en el siglo XVI" en Jerónimo Zurita. Su época y su escuela. Zaragoza, IFC, 1986, pp. 321-333.

11 Contreras, J., "La Inquisición en Aragón: estructura y oposición", Estudios de Historia Social, 1, (1977), p. 130 y BenNASSAR, B., "La Inquisición de Aragón y los heterodoxos", Jerónimo Zurita, 63-64, (1991), pp. 89-91. 
clttem, attendido estamos informados que los christianos nuevos hazen representaciones y falsas ${ }^{12}$ en las quales tractan de cossas muy profanas y que desdizen a todo bueno y virtuoso costumbre de nuestra religión cristiana. Por tanto, mandamos so pena de excomunión y de veinte escudos applicaderos para jocalías de la iglesia, la qual mandamos al vicario exequute con rigor y nos de aviso della para que probeamos del remedio que convenga ${ }^{13}$."

La ruptura de la convivencia entre ambas Comunidades se torna clara en las últimas décadas del siglo XVI. Agrupados en una cofradía bajo las advocaciones de Nuestra Señora de la Esperanza y San Miguel, los cristianos viejos intentan entre 1589 y 1592 con el apoyo de la Orden de Calatrava excluir o limitar la participación morisca en la política y justicia municipal, práctica común a otros Concejos aragoneses ${ }^{14}$. Interpuestos pleitos sobre el tema ante el Consejo de Ordenes en Madrid y los tribunales de Zaragoza por los cristianos nuevos, los visitadores calatravos censuran en 1602 su libertad de gestión en el Concejo calandino y comentan: «están muy libres y levantados contra la Orden» ${ }^{15}$. Los abusos del alcaide

\footnotetext{
12 Falsas: farsas.

13 Archivo Parroquial de Calanda, Primer Libro de Defunciones, Mandato de visita con fecha 2 de enero de 1593 , fol.219v. Sobre estas obras teatrales moriscas y las razones de su prohibición en el reino aragonés, véase YNDURAIN, F., Los moriscos y el teatro en Aragón. Auto de la destrucción de Troya y Comedia pastoril de Torcato. Zaragoza, IFC, 1986 y MATEOS, J.A., "Municipio y teatro en Daroca (siglos XV-xvII): de los entremeses del Corpus a la Casa de Comedias", Criticón, 68, (1996), pp. 15-16.

14 Estos conflictos de poder se dan, por ejemplo, en Caspe. En esta villa, como en muchas poblaciones aragonesas de señorio habitadas por moriscos y cristianos viejos, las dos Comunidades disponían de Concejos propios. Fracasados los intentos de integración inmediatos tras la conversión, el Justicia cristiano viejo intervenía a mediados del siglo xvide facto en causas civiles y criminales relativas a los nuevos convertidos, facultad del alcalde morisco. Véase COLAS, G., La bailia de Caspe en los siglos XVI y XVII. Zaragoza, IFC, 1979, pp. 29-31, 76-80. Problemas de integración política en un Concejo único para ambas Comunidades similares a los de Calanda podian tener lugar de igual modo en municipios de realengo. Con motivo de una insaculación efectuada en Daroca en 1587-88, tres delegados de la minoritaria población morisca suplican el primero de enero de 1588 ante el Concejo "que la ciudad los ampare a los del barrio de la Cristiandad Nueva para hazerlos insecular en los officios de la ciudad". El Concejo remite la solución al Justicia y a los diputados responsables, previa consulta con Juan del Pueyo, el comisario real encargado de realizar dicha insaculación. Debe hacerse notar que estas demandas de integración política chocaban con la creciente cerrazón interna de la oligarquía municipal a fines del siglo xv. De hecho, un estudio de las Actas del Concejo de Daroca conservadas entre 1526 y 1609 revela la carencia de acceso por los vecinos moriscos a los principales cargos municipales. Véase Archivo de Protocolos Notariales de Daroca, Tomás Zorrilla, 1587, (1479), 1 de enero de 1588 y MATEOS, J.A., «El Concejo darocense durante el último cuarto del siglo xvI: tendencias de una oligarquia», Jerónimo Zurita, 65-66, (1992), pp. 7-13.

15 Archivo Histórico Nacional, Consejo Calatrava, legajo 4399, cuadernillo suelto, fol. $2 v$. Para más detalles, Serrano, E., "Las visitas de la Orden de Calatrava al reino de Aragón en el siglo XVI", en Floresta histórica. Homenaje a Fernando Solano Costa. Zaragoza, IFC, 1984, p. 99. Sobre la actuación del alcaide Rosales, SánChez, P. y Serrano, E., “Moriscos, Inquisición...", op. cit., pp. 356-361.
} 
Andrés de Rosales, máxima autoridad judicial en la villa entre 1561 y 1591 , contribuyen a agravar la tensión reinante. Ante la desconfianza mutua, muchos acaparan armas y pólvora, práctica facilitada por su contrabando ligado a la frontera. Un informe inquisitorial relataba asi ya a comienzos del reinado de Felipe II que labradores y trajineros moriscos de Calanda y Gea de Albarracín introducían en el reino de Valencia estas mercancías fabricadas por cristianos nuevos de Villafeliche ${ }^{16}$.

La presión desatada sobre los moriscos calandinos produce sus respuestas en el último cuarto de la centuria. Los cristianos nuevos asesinan a mosén Peralta, vicario de Foz, en mayo de 1577 y al Justicia de Calanda Gaspar Méndez en abril de 1602, asi como planean atentar contra el alcaide Rosales en mayo de 1583 y julio de 1586. El temor a represalias induce a algunos moriscos de Calanda implicados a buscar refugio en Comunidades de cristianos nuevos aragonesas o catalanas próximas. Estos contactos entre moriscos y la posible práctica ocasional del bandidaje por los huidos, unida a la ejercida por delincuentes habituales, provocan la aparición de rumores sobre un alzamiento general y la reacción de las autoridades. El Santo Oficio se siente legitimado así para actuar con extrema severidad: el mayor número de procesos y condenas de moriscos calandinos se registra entre 1595 y 1609. En suma, una vez desatado, el ciclo de violencia incluye aspectos cada vez más diversos - culturales, económicos y políticos, amén de rencillas personales - abarca un espacio geográfico más extenso e involucra a un mayor número de instituciones y grupos sociales.

Como resultado de la confluencia de los conflictos relatados, la anarquia reinante en Aragón alcanza su culminación en el año 1588. El relato del notario Baltasar Royo resulta un fiel exponente de la preocupación suscitada no sólo entre los grupos dirigentes, sino entre sectores sociales acomodados del reino más amplios. Como principal consecuencia, se ha señalado que este temor habría operado en beneficio de causa real frente a la fuerista. Fruto de una premeditada estrategia por parte de Felipe II, los fuertes brotes de violencia acaecidos entre 1585 y 1588 habrian permitido asi a la monarquía comparecer ante sus súbditos en Aragón como la única fuerza capaz de devolver la paz al territorio.

En defensa de esta teoría se ha indicado que, en contraste con la inhibición mostrada por la monarquía en sofocar la delincuencia reinante en Aragón durante la mayor parte de siglo, la reacción de Felipe II en 1588

16 Carrasco, M.S., El problema morisco..., op. cit., pp. 15, 31-32, 50. 
será muy rápida y decisiva para la definitiva remisión del problema ${ }^{17}$. En los últimos meses de 1588 la represión emprendida por el gobernador, tras el fracaso del Justicia, y el perdón concedido a los implicados en las alteraciones del Norte aragonés pacificó la Montaña. Los últimos focos de bandolerismo en el valle del Ebro, incluida la cuadrilla de los «moros de la venganza", eran eliminados a principios de 1589 merced a la utilización del discutido Privilegio de los Veinte por parte de la ciudad de Zaragoza según instrucciones del monarca.

Las restantes convulsiones sociales citadas en el texto se sofocaron con idéntica rapidez ${ }^{18}$. Don Hernando de Aragón, duque de Villahermosa y conde de Ribagorza, es llamado a Madrid en 1588 con objeto de negociar la incorporación de la Ribagorza a la Corona. Debilitado por los graves conflictos vividos en el territorio, éste accederá a vender su estratégico condado a Felipe II. La toma de posesión definitiva será efectuada el 6 de marzo de 1591 por don Alonso Celdrán en nombre del monarca. Ese mismo año de 1588 Felipe II, tras convocar una Junta extraordinaria en el Pardo, decide la conveniencia de proceder a un segundo desarme de los moriscos aragoneses, tras el efectuado en 1575. Ya con el ejército castellano acuartelado en Aragón tras las alteraciones de 1591, este desarme será realizado en 1593.

\section{EL CONTEXTO LITERARIO: LA RELACIÓN DE SUCESOS Y LA LITERATURA DE PRONÓSTICOS}

El texto analizado en el presente estudio es una relación de sucesos ${ }^{19}$. Este tipo de documentos se caracterizan por narrar un determinado acontecimiento ocurrido -o en ocasiones inventado, pero verosímil- con el fin

17 Colas, G. y Salas, J.A., Aragón en el siglo xvi..., op. cit., pp. 395-411, 579-580.

18 Para el condado de Ribagorza, Colas, G. y Salas, J.A., Aragón en el siglo xvi..., op. cit., pp. 147-150. Sobre el desarme morisco dictado en 1588 y su posterior ejecución en 1593, REGLA, J., Estudios..., op. cit., pp. 73-76.

19 Entre los principales repertorios de relaciones de sucesos, merecen destacarse los trabajos de Alenda, J., Relaciones de solemnidades y fiestas públicas en España. Madrid, Sucesores de Rivadeneyra, 1903; Carareres, S., Ensayo de una bibliografía de los libros de fiestas celebrados en Valencia y su antiguo reino. Valencia, Sucesores de Rivadeneyra, 1926; Agullo, M., Relaciones de sucesos, I. Años 1477-1619. Madrid, CSIC, 1966; Rodriguez Moniño, A., Diccionario bibliográfico de pliegos sueltos poéticos (siglo Xvi, Madrid, Castalia, 1970 y Nuevo diccionario de pliegos sueltos poéticos (siglo xvi). Madrid, Castalia, 1997; Garcia de Enterría, M.C., Catalogo de los pliegos poéticos españoles del siglo xvil en el British Museum de Londres. Pisa, Giadnini, 1977; Delgado, J. y MaRTin, J., Repertorios bibliográficos de impresos del siglo xVI (españoles, portugueses e iberoamericanos). Madrid, Arco Libros, 1993; Simón, J., Bibliografía regional y local de 
de informar, entretener y conmover al público lector. Los temas abarcados por estos textos resultan muy variados: hechos histórico-políticos, acontecimientos familiares en la Casa Real, fiestas religiosas, cívicas o cortesanas... Las relaciones de sucesos incluyen de igual modo en sus páginas los relatos de viajes o la narración de sucesos extraordinarios, como los milagros, las catástrofes naturales o las desgracias personales.

La forma adquirida por estas narraciones, como sucede con su temática, es muy diversa ${ }^{20}$. Las relaciones de sucesiones se hallan tanto manuscritas como impresas, en verso como en prosa. Su extensión resulta asimismo variable. Pueden constar de un solo pliego o llegar a adquirir el formato de un libro más o menos voluminoso. Sin embargo, la mayoría de estas narraciones - como el ejemplo elegido para este estudio-son muy breves. Constan por lo común de un sólo pliego compuesto por dos o cuatro hojas.

Las relaciones de sucesos aparecen en España en el siglo XV, ligadas al género epistolar: la carta-relación, que informa a un particular de algún hecho del que fue testigo el emisor ${ }^{21}$. En el Quinientos surge la relación de sucesos como género autónomo, aunque en convivencia siempre con el epistolar. Dirigida gracias a la imprenta a un público más amplio, alcanza su apogeo en el siglo XVII, sobre todo en los reinados de Felipe IV y Carlos II ${ }^{22}$. El paulatino declive de las relaciones se encuentra unido al éxito de las gacetas, avisos y

España, I: Impresos localizados (siglos xv-xviI). Madrid, CSIC, 1976 y Relaciones de actos públicos celebrados en Madrid (1541-1650). Madrid, CSIC, 1982; ETTINGHAUSEN, H., La guerra del Segadors a través de la prensa de lépoca. Barcelona, Curial, 1993 y Noticias del siglo xvi: relaciones es. pañolas de sucesos naturales y sobrenaturales. Barcelona, Puvili, 1995. Como principales Simposios sobre el tema hasia la fecha, Garcia de EnTERrí, M.C. et alii (eds.), Las relaciones de sucesos en España (1500-1750). Alcalá de Henares, Servicio de Publicaciones de la Universidad de Alcalá y Publications de la Sorbonne, 1996 y LóPEz, S. y PENA, N., (eds.), La fiesta: actas del I/ Seminario de relaciones de sucesos. El Ferrol, Sociedad de Cultura Valle Inclán, 1999.

20 Esta diversidad formal provoca controversias a la hora de definir la "relación de sucesos". Víctor Infantes considera conveniente en aras de un mejor análisis restringir el concepto a los pliegos impresos. Así, la relación de sucesos sería "un impreso breve de carácter informativo y no periódico". José Simón, por el contrario, entiende que las relaciones manuscritas e impresas coexisten y no se diferencian. Véase al respecto INFANTES, V., “¿Qué es una relación? (Divagaciones varias sobre una sola divagación)", en GARCíA UE ENTERRIA, M.C. et alii (eds.), Las relaciones de sucesos... op. cit., pp. 203-216 y SIMÓN, J., Relaciones de actos públicos..., pp. 206-207.

21 Catedra, P.M., "En los origenes de las epístolas de relación» en Garcia de ENTERría, M.C. et alii (eds.), Las relaciones de sucesos..., op. cit., pp. 33-64.

22. Caro Baroja, J., Ensayo sobre la literatura de cordel. Madrid, Revista de Occidente, 1969; Garcia DE ENTERRIA, M.C. Sociedad y poesia de cordel en el Barroco. Madrid, Taurus, 1973; REDONDO, A., "Les relaciones de sucesos dans l'Espagne du Siécle d'Or: un moyen privilegié de transmission culturelle" en Les médiations culturelles. París, Publications de la Sorbonne Nouvelle, 1989, pp. 55-67; Ettinghausen, H., Noticias del siglo xvil.. op. cit., y «The news in Spain: Relaciones de sucesos in the Reigns of Philip III and IV", European History Quarterly, XIV, (1984), pp. 1-20. 
diarios en el siglo XVIII. En contraste con la narración ocasional de las relaciones de sucesos, estos nuevos medios de comunicación amplían el horizonte informativo del lector al contar las noticias de manera periódica. A diferencia del resto de Europa, donde desaparecen con rapidez ante el auge de las gacetas, las relaciones de sucesos perduran durante largo tiempo en España como relato no periódico de un hecho ocasional.

Dentro de esta evolución, el siglo XVı asiste a la creciente difusión de las relaciones de sucesos entre un público más amplio y variado gracias a diversos factores ${ }^{23}$. La invención de la imprenta permite su producción en serie como pliegos sueltos en una escala desconocida hasta entonces. Al igual que sucede con los libros, la mayor baratura de las relaciones impresas contribuye a difundir el hábito de la lectura. Con todo, el fenómeno decisivo viene constituido por la expansión en España de la educación en todos los niveles formativos, impulsada por la mayor prosperidad general y el apoyo de los poderes públicos. El indudable aumento de la alfabetización consiguiente incrementa el número potencial de lectores, quienes con frecuencia transmiten a su vez mediante el recitado el contenido de las relaciones entre los iletrados.

Esta mejor formación proporcionada a sectores más amplios de la población en el siglo xvı posibilita el incremento de los cultivadores de la crónica histórica y la relación de sucesos. El afianzamiento del Estado moderno en Europa durante la centuria como institución política, apoyado en una administración creciente, se revela un fenómeno paralelo a la nueva valoración de las lenguas nacionales como formas de expresión. El castellano adquiere así en España y Europa un prestigio cultural y un vigor literario desconocido hasta entonces. El mayor aprecio del idioma autóctono se plasma en el surgimiento de Gramáticas, dedicadas a fijar su correcto uso. El fortalecimiento de la identidad nacional y la expansión del Imperio Español en Europa y América introduce una nueva concepción de la historia y una clara renovación formal en la crónica y prosa documental ${ }^{24}$.

23 Livre et lecture en Espagne et en France sous l'Ancien Régime. París, A.D.P.F., 1981; Cheval.IeR, M., Lectura y lectores en la España de los siglos xvi y xvII. Madrid, Turner, 1976; BoTREL, J-F., y SALAÜN. S., (eds.) Creación y público en la literatura española. Madrid, Castalia, 1974; FRENK, M., "Lectores y oidores. La difusión oral de la literatura en el Siglo de Oro", en Actas del Séptimo Congreso de la Asociación Internacional de Hispanistas. Roma, Bulzoni, 1982, vol. I, pp. 101-125; Garcia de EnterRia, M.C., "Lectura y rasgos de un público", Edad de Oro, XII, (1993), pp. 119-130; KAGAN, R.L., Universidad y sociedad en la España Moderna. Madrid, Tecnos, 1981; NALLE, S. T., "Literacy and Culture in Early Modern Castile», Past and Present, 125, (noviembre, 1989), pp. 65-96; REDONDO, A., (ed.) La formation de l'enfant en Espagne auX XVI et XVII siècles. París, Publications de la Sorbonne, 1996.

24 Sobre el particular, véase la síntesis de RodRiguez CACHO, L., "Historias y experiencias" en Lopez Estrada, F et alii, Siglos de Oro: Renacimiento, (en Rico. F., (ed.) Historia y Critica de la literatura española, vol.2. suplemento 1) Barcelona, Crítica, 1991, pp.109-123. 
Junto a los relatos dedicados al descubrimiento y conquista de tierras americanas, esta diferente consideración del pasado favorece tanto la escritura de crónicas sobre los reinos peninsulares como de narraciones de carácter más local sobre la historia de villas y ciudades.

El caso específico objeto de este estudio se cuenta entre las relaciones de sucesos manuscritas. La narración de Baltasar Royo se encuentra redactada en prosa en las seis últimas páginas de uno de sus protocolos que recoge documentación notarial varia fechada entre los años 1571 y 1585 . El relato se halla antecedido por un par de páginas que contienen un poema de ocho versos en latín y tres sucesivas traducciones y glosas de éste en castellano. El poema viene a constituirse en un pronóstico que anuncia hechos luctuosos para el año 1588. La relación de sucesos realizada por el autor tendría por objeto confirmar la veracidad de esta predicción.

El carácter manuscrito y la redacción en prosa de la relación de Baltasar Royo condiciona en alto grado el modo de exposición y composición estilística del documento. Estos aspectos formales se hallan al servicio del tipo de comunicación establecida con el lector potencial. Con claros vínculos con el género epistolar ${ }^{25}$, el relato sin embargo no se halla dirigido a ningún receptor real o ficticio ni incluye ninguna introducción dedicada a informar al público lector sobre la importancia de los hechos narrados. El texto parece más bien elaborado por Baltasar Royo para su uso personal o a lo sumo, para su lectura o recitado entre un círculo restringido de amigos o conocidos. Dicha orientación decisiva del manuscrito al ámbito privado lo diferencia en gran medida de las relaciones de sucesos impresas. Estas eran destinadas a un público anónimo y más numeroso, asumían una acusada intención comercial y se veían sujetas a los controles oficiales por medio de la censura.

De acuerdo con esta remisión al ámbito privado, el autor utiliza un estilo breve, sencillo y seco. Su escrito busca en esencia la narración inmediata de los hechos, con nulas pretensiones literarias. En este caso, la intención informativa y la noción de verdad histórica características de las relaciones de sucesos se ven reforzadas por el oficio de notario ejercido por Baltasar Royo. Con todo, el mismo carácter privado del relato permite a su autor un tono descuidado. Así, si bien todos los sucesos descritos se refieren al año 1588 , su concatenación en el texto es algo defectuosa. La carencia de nexos para introducir nuevos hechos se ve

25 Sobre el tema, Gafcia de Enterria, V., "Relaciones de sucesos en forma de carta: estructura, temática y lenguaje» en GarciA DE ENTERRIA, M.C. et alii (eds.), Las relaciones de sucesos... op. cit. pp. 177-184. 
agravada en ocasiones por saltos temporales entre unos sucesos y otros. Las referencias cronológicas presentes en el texto refuerzan esta cierta imprecisión temporal al remitir con frecuencia de forma sucinta al mes en que acaecieron los hechos narrados. La constatación de que ciertos acontecimientos tuvieron lugar en 1588 ganaría prioridad en el relato sobre su fijación exacta en el tiempo, dado que su principal fin es justificar el pronóstico que lo antecede.

Tras exponer estos rasgos de su redacción, parece claro que el escrito de Baltasar Royo no se hallaba destinado a una difusión amplia, pública e inmediata entre sus coetáneos de los sucesos narrados, por todos conocidos. Orientado a una circulación más bien restringida, el texto se proyecta hacia el futuro. De algún modo, este manuscrito pretende constituirse para el porvenir en modesta y tosca crónica de los sucesos del año 1588 , asi como dar testimonio de la predicción que los había anticipado. No obstante, resulta evidente que el autor no ha realizado ningún trabajo preliminar de búsqueda de documentación orientado a permitir relatar de forma ordenada y detallada los hechos, así como a proporcionar una valoración o explicación de los mismos. En este sentido, la exposición de las noticias en el texto se muestra muy vecina a su transmisión oral, con deformaciones y bulos añadidos.

El relato de Baltasar Royo guarda evidente vestigios de esta relación entre la cultura oral y la escrita, la narrativa escrita y el relato popular o folklórico. Debido a la lejanía en el espacio de los sucesos y como resultado de su transmisión oral, la derrota de la Armada Invencible es expuesta de forma imprecisa y con ciertas exageraciones, como ocurre con la mención del gran número de muertes debidas a la mala calidad de los alimentos. El pasaje de la conspiración morisca en el Bajo Aragón dirigida por el caudillo Germán incluye aspectos fantásticos, como la mención de la corona de oro con armas del turco ${ }^{26}$, muy ligados a la fantasía popular y al relato oral. La personificación del bandolerismo aragonés en su figura más famosa, Lupercio Latrás, demuestra su fuerte impronta en la imaginación popular, similar a la ejercida por los bandidos catalanes más famosos ${ }^{27}$.

${ }^{26}$ Como ejemplo, véase Baralos, M., "Tesoros moriscos y picaresca», Espacio, Tiempo y Forma, IV, 9, (1996), pp. 11-24.

27 Sobre la figura de Lupercio Latrás, véase COLAS, G. y SALAS, J.A., Aragón en el siglo xvı..., op. cit., pp. 230-276. La visión popular del bandolero catalán en este período ha sido tratada por diversos autores. Entre otros, consúltese REGLA, J. y FUSTER, J., Joan Serrallonga: vida i mort del famós bandoler. Barcelona, Aedos, 1961; FuSTER, J., El bandolerisme català: la llegenda. BarceIona, Aymà, 1963; Garcia de Enterria, M.C., Sociedad y poesia... op. cit., y Alcoberro, A., "Visió popular del bandolerisme del segle Xvil: una aproximació" en Primer Congrés d'História Moderna de Catalunya. Barcelona, Universitat de Barcelona, 1984, vol. II, pp. 569-577. 
Figura compleja, sus desafíos ocasionales al poder real —en 1588 llega a poner a precio la cabeza del virrey-, su prestigio entre sus connaturales del Pirineo y su fama como bandolero le habían ganado en Aragón respaldos en amplios sectores populares y las simpatias de ciertos grupos fueristas, sentimientos expresados en crónicas y pasquines de la época.

El análisis de este relato mueve asimismo a considerar la posible influencia recibida por el autor por parte de las relaciones de sucesos impresas, en auge espectacular a fines del siglo xvI. De forma significativa, la narración de Baltasar Royo recoge temas y personajes en boga en esta literatura de pliegos sueltos ${ }^{28}$. Así ocurre con la figura del bandolero, de gran impacto en la imaginación popular y protagonista común de relatos de crímenes. El morisco recibe un interés creciente en los pliegos sueltos, unido al recurrente tema de la amenaza turca. Los relatos de catástrofes se verían representados por la derrota de la Armada Invencible.

Con todo, el tratamiento dado a este material por Baltasar Royo difiere en grado sustancial de la literatura impresa de sucesos, orientada de forma cada vez más acusada al mercado ${ }^{29}$. Personajes tan arquetípicos como el morisco o ei bandolero no se ven así cargados en este relato de tintes negativos como resultado de planteamientos maniqueos, muy comunes a las relaciones de sucesos, en especial durante el siglo XVII. La descripción de los crímenes narrados en el texto realizada por el autor se halla ausente del tremendismo tan característico de los pliegos sueltos, destinado a impresionar al lector. Los datos sobre la expedición de la Armada Invencible carecen en este sentido de las enormes exageraciones ligadas a los relatos de catástrofes, si bien se hallan sujetos a otras inexactitudes derivadas de su transmisión oral.

Este último episodio, la empresa de la Armada Invencible, resulta en extremo idóneo para introducir algunas indicaciones sobre las actitudes y

\footnotetext{
28 Rodriguez Moniño, A., Nuevo diccionario bibliográfico...op. cit. pp. 29-48.

29 Garcia de Enterbia, M.C., Sociedad y poesia... op, cit., Redondo, A., «Las relaciones de sucesos en prosa (siglos XVI y XVII)" y "Características del periodismo popular en el Siglo de Oro", Anthropos, 166-167, (mayo-agosto 1995), pp. 51-59 y 80-85, "L.e bandit à travers les pliegos sueltos du XVI and XVII siècles" en Le bandit et son image au Siècle d'Or, Madrid.Paris. Universidad Autónoma, Casa de Velázquez-Publications de la Sorbonne, 1991, pp. 123-138 y “L'image du morisque (1570-1620), notamment a travers les pliegos sueltos. Les variations d'une alterité» en Les représentations de l'Autre dans l'espace ibérique et ibéro-américain. Paris, Publications de la Sorbonne Nouvelie, 1993, vol. II, pp. 17-31; EtTINGHAuSEN, H., «Sexo y violencia: noticias sensacionalistas en la prensa del siglo XVII", Edad de Oro, XII, (1993), pp. 95-107 y "Política y prensa popular en la España del siglo XVIl", Anthropos, 166-167, (mayo-agosio 1995), pp.86-90; CAMPO, $V$., "La historia y la política a través de las relaciones en verso en pliegos sueltos del siglo XVII" en Garcia de Enterfía, M.C. et alii (eds.), Las relaciones de sucesos... op. cit., pp.19-32.
} 
propósitos del autor. Con su elección, Baltasar Royo demuestra una mayor libertad para elegir los temas de su relato manuscrito al hallarse fuera del control de la censura. De hecho, la narración de derrotas no era nada frecuente en las relaciones impresas de la época, cada vez más consagradas a conmemorar las victorias españolas en beneficio de la propaganda política. Como actitud frente al poder, el escrito de Baltasar Royo elude por igual tanto la sátira política como la exaltación del monarca, rasgo este último cada vez más acusado de las relaciones impresas durante los siglos XVI y XVII. Por último, a diferencia de muchos pliegos sueltos en sus múltiples variantes -historias piadosas, relatos de crímenes, narraciones bélicas y políticas-, el presente manuscrito no intenta transmitir a su receptor ningún mensaje didáctico o doctrina moral para el futuro.

La remisión al ámbito privado del escrito de Baltasar Royo contribuye de igual modo a explicar la existencia del pequeño pronóstico en latín que lo antecede ${ }^{30}$. Esta literatura de presagios y pronósticos, vinculada muchas veces con la astrología y unida a la publicación de almanaques y calendarios, debió de tener amplia difusión en el Siglo de Oro ${ }^{31}$. Sus manifestaciones se conocen de forma parcial y defectuosa al restringirse su circulación impresa como resultado de la presión de la Iglesia, que consideraba estas prácticas vecinas a la superstición. De ahí su propagación mediante pliegos manuscritos, como sucede en el caso presente. De hecho, las tres traducciones sucesivas recibidas por el pronóstico -la más fiel al original es la última - revelan un cierto grado de difusión y conocimiento del poema en determinados círculos cultivados.

Como ya sucedía con el relato histórico, las características del citado pronóstico recalcan de nuevo las distintas posibilidades de expresión ofrecidas por la literatura impresa y la manuscrita. Así, Baltasar Royo utiliza una predicción para exponer no sólo las violentas convulsiones sociales

30 Agradezco a la profesora de la Universidad de Zaragoza María del Mar Agudo su ayuda en la transcripción de dicho texto.

31 Muñoz, S., Inquisición y ciencia en la España Moderna. Madrid, Editora Nacional, 1977; Martinez Arancón, A., La profecia. Madrid, Editora Nacional, 1975, pp. 91-100 y Redondo, A., "Características del periodismo popular en el Siglo de Oro", Anthropos, 166-167, (mayo-agosto 1995), p. 84. Consúltese como ejemplo las menciones de pronósticos y discursos astrológicos impresos por los talleres tipográficos zaragozanos durante el siglo XVII, concentradas en su mayoria en las décadas de los cuarenta y ochenta, en JIMÉnEZ CATALAN, M., Ensayo de una tipografía zaragozana en el siglo xvII. Zaragoza, Tipografía la Académica, 1925, pp. 199, 207, 225, 369$370,373-374,379,383,391-392,410-412,419$ y 482 . El siglo xVIII aporta referencias mucho más precisas sobre este género de obras y sus autores. Véase AGUILAR, F., La prensa española en el siglo XVII: diarios, revistas y pronósticos. Madrid, CSIC, 1978, pp.12-21 y 53.125 y MERCADIER, G., Diego de Torres Villarroel. Masques et miroirs. Paris, Librairie Honoré Champion, 1976, vol. I, pp. 294-314. 
del Aragón de 1588, sino la seria derrota de la monarquía católica española en su empresa de conquistar Inglaterra, un país protestante. Por el contrario, los pronósticos impresos en los siglos XVI y XVII rara vez anunciaban sucesos en España por miedo a la censura. De hecho, como medida cautelar, bastantes de estos pronósticos situaban sus predicciones en tierras islámicas y su autoría era atribuida a sabios moros y turcos. Sus contenidos se irán tornando más y más irrelevantes para merecer ya en la primera mitad del siglo XVIII la aprobación de la censura, lo que permitirá el rotundo éxito de los almanaques. Pese a todo, tras el estallido del motín de Esquilache, los ilustrados españoles decidieron en 1767 prohibir la circulación tanto de romances de ciego como de pronósticos, ante el temor de que éstos pudieran incitar de algún modo al vulgo a nuevas revueltas.

\section{CONCLUSIONES}

Como conclusiones, considero conveniente destacar que las convulsiones políticas y sociales acaecidas en Aragón durante el siglo XVI, en pleno auge del Imperio español, demuestran haber dejado una impresión muy nítida en la memoria de los coetáneos. Esta percepción de asistir a sucesos excepcionales se agudiza a fines de la centuria al transmitir la sucesiva acumulación de conflictos la idea de una violenta subversión del orden establecido. Más allá de los cronistas oficiales y los círculos literarios, se despierta entre ciertos grupos sociales acomodados del reino con acceso a una cierta educación la necesidad de transmitir estos hechos para la posteridad mediante su plasmación escrita.

El relato del notario Baltasar Royo, que sin lugar a dudas no se trata de un ejemplo aislado, se constituye así en testimonio de una coyuntura histórica concreta. De acuerdo con sus propósitos, el autor hace converger en este escrito dos géneros literarios de gran difusión en España durante el Siglo de Oro: la relación de sucesos y la literatura de pronósticos. En pleno auge de la imprenta, el carácter manuscrito del texto y su probabie remisión al ámbito privado confieren al documento en su forma y contenido unas marcadas diferencias respecto a la literatura de pliegos sueltos. Relaciones y pronósticos impresos se vieron sujetos durante los siglos XVI y XVII a fuertes condicionantes como resultado tanto de la censura como de su decisiva orientación hacia el mercado. Por el contrario, la narración de Baltasar Royo revela una mayor libertad en la elección de ios temas y una pretendida objetividad al renunciar a comunicar al receptor cualquier mensaje moral. De estilo sencillo y tosco, manifiesta por igual las miras locales del autor y una cierta carencia de espíritu crítico al 
describir los sucesos. De hecho, la ausencia de una reelaboración cuidada de las noticias recibidas ha permitido la conservación en el documento de vestigios evidentes de su previa transmisión oral.

A la luz de todo lo expuesto, estimo oportuno someter a una mayor atención a todas estas manifestaciones escritas, con nexos evidentes con la literatura de pliegos sueltos. La concentración de las investigaciones actuales en el estudio de documentos impresos puede conducir a una visión en exceso sesgada de la circulación de noticias en España durante la Edad Moderna. Al margen de los controles oficiales, estos manuscritos permiten una cierta difusión de temas más problemáticos y difíciles de hallar en la literatura impresa. Alumbran asimismo nuevos datos sobre la percepción de diversos sucesos por parte de los contemporáneos y testimonios de indudable interés sobre la mentalidad de la época. Se impone, por tanto, un mejor conocimiento de las características y grado de circulación de todos estos escritos para poder determinar su papel efectivo en la literatura y cultura del Antiguo Régimen.

\section{Apéndice documental}

Archivo Municipal de Alcañiz, Sección de Protocolos Notariales, Baltasar Royo, notario de Zaragoza, 1571-85, (1810), fol. 943r-946v.

Estos versos se allaron en Roma en la sepultura de un obispo que havía muchos anyos que era defunto

Post milles expletos a partu virginis anno et post quingentos gressus ab orbe datus octuagessimus octabus terribilis annus nigruet et secum tristia fasta feret si non hoc anno sustancia dicidat orbis si nichilum celum et terram fretumque ruat cuncta tamen mundi sursum ibunt adque diorsum imperia et luctus undique grandinis erit

Traduction del doctor y maestro Vinzet

Passados sobre mil quinientos anyos y siete sobre ochenta de la era que Dios vino a pagar por nuestro danyos oh mundo, que ha de dar tu estrella fiera si al cabo no te da cassos estranyos y el cielo, tierra y mar la ora postrera sus reynos llorarán los potentados de sus sillas y cetros derribados 
Traductio y glosa del doctor Fuster

Después que el rey de la tierra y cielos

Christo Redemptor Nuestro fue humanado

mii quinientos ochenta y ocho anyos

ser se verá éste un anyo de gran cuydado

$Y$ si en el mundo todo no fenece

la tierra, aire y mar y todo lo criado

por lo menos del orbe los emperadores

rebueltos se verán en bellicos furores

Traduction y glosa de (en blanco)

Después del parto de la Virgen pura

mil y quinientos y ochenta y ocho anyos

verase ser un anyo terrible y de amargura,

el qual traerá consigo terribles hados

Y si en él no fenece en roces todo el orbe

sin quedar d'el tan sólo un átomo

por lo menos del mundo los imperios

rebueltos se verán en furores bellicos

Anyo de MDLXXXVIII, lunes Sancto y a $x \mid$ de março fue derribado, desolado y destruido el lugar de Codo, que es del abad de Rueda, en el reyno de Aragón, junto a Belchite, por los montanyeses sus enemigos, con pérdida de pocos cristianos. $Y$ los moros con su familia se recogieron en la Pobla ${ }^{32}$ y Sástago.

El mesmo día la villa de Castellot ${ }^{33}$ escribió una carta a los lugares de las Vaylías dixendo estavan sobre la Ginebrosa trescientos moros, matando y hiciendo danyo. $Y$ porque la tierra recelava los moros se havían de levantar, se albolotó con este nuevo caso. Tanto que, siendo el aviso a las seis de la tarde, cada qual procurava salvar la vida yéndose a los montes y otros a la yglesia con la ropa que podían, y a defender sus hijos y mujeres. Teniendo por cosa cierta ser muertos a la manya(na), y los moros haverse levantado como se decía y pretendía, estuvimos muy confusos por la falta de armas y munición. Antes de la medianoche vino otro aviso en que decían se sosegasen porque no era nada y que dicho albolote havían causado unos pescadores en el río Gadalop ${ }^{34}$. Con todo esto, se juntó la tierra en Cantavieja a efecto de proveerse armas. Y porque por la sospecha que la

32 La Pobla: La Puebla de Albortón.

33 Castellot: Castellote.

34 Gadalop: Guadalope. 
tierra tenía havian inviado síndicos a Çaragoça a saber lo que passava y proveer armas y lo necesario. Y estando ellos allá sucedió dicho alborote. En todo el reino se tuvo por cierto. Los diputados querían inviar soldados, como lo hicieran si los síndicos no aseguraran no era como se decía. Y ansí, venidos dichos síndicos, se juntó la tierra en Cantavieja y se nombró por capitán a Joan de Castellot, de Cantavieja, en alférez al jurado mayor de Aliaga y en sargento al jurado mayor de Castellot, llamado Marco Çit. Y mandaron proveher arcabuces y munición de bala. $Y$ adecenaron toda la tierra. Y lo mismo hiço el resto del reino.

El día de la feria de Pina, Lupercio Latrás, capitán de los montanyeses, con poca gente fue a dicho lugar de Pina y le saqueó y quemó aprovechándose mucho. $Y$ dixeron haver muerto más de quatrocientas personas a cuchillo.

Tuvo sitio sobre Sástago y le mataron un sobrino con pérdida de tres cristianos. Y murieron más de quarenta moros.

Albarracín, Teruel, Daroca, Calatayud, Caspe y Alcañiz inviaron a Çaragoça los primeros de mayo dicho anyo muchos soldados. El efecto que hicieron se dirá abaxo.

En el mesmo anyo huvo grandíssima guerra en el condado de Ribagorça entre el duque y los vasallos. $Y$ fue saqueado Graus en el agosto passado, día de San Bartolomé.

Los moros de Calanda se fortificaron y proveyeron de muchas armas. $Y$ los de la Puebla ${ }^{35}$ fueron muchos en número porque en ella se juntó Codo, Vinaceyt ${ }^{36}$, Aceylla ${ }^{37}$, la Çayda ${ }^{38} y$ otros dos lugares y muchos moros valencianos. Tenían allí elegido a un moro de $x x x$ mil ducados por conde y virrey en Calanda. $Y$ en Açcón ${ }^{39}$ tenían nombrado por rey a un moro llamado Germán, hombre de docientos mil ducados de hacienda. Prendióle un aguacil del Santo Officio en el castillo de Azcón ${ }^{40}$, que vino de la Corte sin alborote alguno. Llevaronle a la Corte con todas sus escrituras y con una corona de oro con las armas del Turco que le allaron en un escritorio. $Y$ el mayor dolor que dixo tenía era ver sus papeles en poder de cristianos porque, aunque él muriesse, otro quedava. Passaronle por Çaragoça para la Corte. Lo que más suceiere abaxo se dirá.

\footnotetext{
35 La Puebla: La Puebla de Albortón.

36 Vinaceyt: Vinaceite.

Aceylla: Azaila.

La Çayda: La Zaida.

Açcón: Ascó, municipio sito en la provincia de Tarragona.

40 Azcón: Ascó.
} 
En este mesmo anyo los primeros de março se embarcó en Sevilla la mayor y más poderosa armada que rey cristiano ha tenido por orden de su Majestat. Y fue a nuevamente conquistar los reynos de Ingalaterra y Hislas de Flandres. Su Majestat del rey don Felipe Nuestro Señor quedó en Madrid. Dios les dé buen sucesso.

En el mes de junio dicho anyo salió de Çaragoça el Justicia de Aragón con seis mil de dichos soldados para perseguir a dicho Lupercio Latrás y gastó más de quarenta mil ducados. Y por el mucho gasto que hacía y el poco fruto que de su salida se aguardava, el reino le mandó bolver y quitó la comisión de gastar. Y Lupercio Latrás se subió a la Montanya y tomó la villa de Aynsa y fortaleció en ella.

En el mes de agosto dicho anyo fueron Miguel Royo, notario de Mirambel, Antón Tomás, de Castellot, notario, y Joan Vivo, de Aliaga, por síndicos de las Vaylías a Çaragoça para poner la unió y ermandat en el reyno para perseguir malhechores.

El día de la feria de Pina vino Lupercio Latrás con su companya sobre Pina y degolló y mató seisçientas personas en dicho lugar, por lo qual fue persiguido del Justicia de Aragón, diputados y del governador. $Y$ se gastaron muchos ducados y hovo muchas muertes. Fue este Lupercio un grandíssimo bandolero.

Por mayo de 1588 el rey don Filipe de Austria Nuestro Señor invió una muy poderosa y grandíssima armada con más de 80 mil hombres sobre Ingalaterra. $Y$ el corsario Francisco Drake, capitán de la Inglesa, les salió en la mar al encuentro. $Y$ se fue nuestra armada retirando y se bolvió sin hacer efecto, muy derrota por la tormenta. Y salió en Vizcaya, quando unas, quando otras. $Y$ porque los que hicieron el biscocho, lo masaron con cal, enfermó la gente y murieron de enfermedad más de 30 mil hombres. Fue el rey advertido de un pronóstico que si yva, se perdería. 